\title{
Cultural Models for Negotiating Guyanese Identity as Illustrated in Jan Lowe Shinebourne's Chinese Women and Other Fiction
}

\author{
Abigail Persaud Cheddie \\ University of Guyana, Guyana
}

Doi: 10.19044/llc.v6no3a1

URL:http://dx.doi.org/10.19044/llc.v6no3a1

\begin{abstract}
Guyanese elementary level pupils are often introduced to the formal sociological study of their country with the expression 'the land of six peoples' - an axiom that can encourage defining self through separatism. Though this expression serves as a concrete Social Studies introduction to children who cannot yet think abstractly, adherence to this fixed and segmenting model as the main measure of conceptualising self and others can become limiting and problematic in a society that is already struggling with defining individual and national identities in a more fluid manner. In her fictional works collectively, Jan Lowe Shinebourne moves towards locating models more suited to the flexible negotiation of the Guyanese identity. To examine how she does so, this paper firstly considers some limitations of the multicultural model and shows how the author introduces her interrogation of this model in her first two novels and in her second novel introduces her exploration of the crosscultural model, then experiments with this model more extensively in her third novel Chinese Women. Finally, the paper briefly highlights how Lowe Shinebourne explores the use of the intercultural model in her fourth novel and the transnational model in her collection of short stories. Ultimately, Lowe Shinebourne manages to elevate the validity of engaging with other models of understanding self, rather than remaining steadfast to the problematic old local multicultural lens.
\end{abstract}

Keywords: Shinebourne; Guyanese identity; cross-cultural; intercultural; transnational; transcultural.

\section{Introduction}

Jan Lowe Shinebourne's novel Chinese Women (2010) explores how race and race relations in Guyana heavily influence the formation of individual and national identities. This is a theme which the author begins examining in her earlier works Timepiece (1986) and The Last English Plantation (1988) 
and which she addresses more comprehensively in Chinese Women and supports with her narrative in The Last Ship (2015). These novels, along with her collection of short stories - The Godmother and Other Stories (2004), can be seen as attempting a search for a suitable cultural model of negotiating identity on the Guyanese landscape. Taken as a body of work, these texts provide a framework for contemplating the limitations and suitability of cultural models used in mapping identity on the post-colonial Guyanese landscape.

In order to examine Lowe Shinebourne's search for this suitable model, this paper highlights how the author's body of work moves from illustrating more fixed to more fluid conceptualisations of identity. Firstly, the paper considers the complications and limitatons of using the multicultural model in a country like Guyana and shows how Lowe Shinebourne launches her search for an appropriate model through the characters in her first two novels Timepiece and The Last English Plantation. I then examine how she introduces the use of the cross-cultural model in The Last English Plantation through her protagonist June Lehall and how she continues applying this model more extensively through her protagonist Albert Aziz in Chinese Women. I show how in this novel she first problematises how post-colonial Guyanese identity is founded on a racialised model of understanding self, then offers a solution through Albert's negotiation of self. Finally, I briefly highlight how Lowe Shinebourne continues to move towards more fluid models by exploring the use of the intercultural model in her third novel The Last Ship and the transnational model in her collection of short stories The Godmother and Other Stories.

One of the earliest approaches to identity in elementary schools in Guyana is through a multicultural model - Guyana is described as 'the land of six peoples.' As a child, this was one of the first axioms that was supposed to help me understand who I was. Though theoretically, this model is used to heighten children's sensitivities to themselves and encourage appreciation for each other, in the same moment that it proposes attitudes of self-acceptance and celebration of others, it confounds and excludes. For one thing, it is a model that merges at its foundation, in unequally problematic parts, elements of history, race, ethnicity and other cultural elements. To begin with, the countable six groups offers a history lesson - a suggestion of the order of arrival and colonisation. Then, the group of six is a model that can be interpreted partly on race and often conflictingly partly on ethnicity. Frank Thomasson (2009) refers to the groups as peoples, listing them as "the indigenous Amerindians, Europeans, Africans, Portuguese (Madeirans), East Indians and Chinese" (p.18), while Winston McGowan (2018) classifies these six groups into five races: "Amerindians, Europeans" (being “...two main groups, Britons and Portuguese..."), "People of African descent, East Indians 
and Chinese" (p.12). To young children, this 'land-of-six-peoples' model, which is sometimes casually re-worded as the 'land-of-six-races,' can create confusion and a synonymy between race and ethnicity and culture. Sometimes, for instance, in some schools' 'Culture Day' performances, pupils are assigned clothing traditionally associated with different racial groups and are expected to interpret these pieces of clothing such as saris and cheongsams, for example, as their 'culture.' Additionally, the word peoples connotes a sense of cultural diversity, implying that the plural condition of the country requires a kind of multiplex interpretation by its citizens, an interpretation which may often be processed in separatist manner.

Further, as children, we were encouraged to interpret ourselves and our friends as fitting into one of these groups of peoples. Yet, how were those who were mixed with two or more of these races or those who outwardly looked like one race but were mixed with another supposed to interpret themselves using this streamlined model? Or how ought those who looked like one race but assumed closer contact with another race or other races, or with no race in particular, to use this model to interpret themselves? Also, how might someone who interchanged his cultural perspective or ethnic understanding of himself depending on social context engage with the ambivalent multicultural model? Further, how might someone processing and exchanging a variety of dynamic influences define himself? Lowe Shinebourne in an interview with Annie-Marie Lee-Loy (2008) shares similar personal experiences growing up in Guyana: "I look Chinese but in fact, my ethnic ancestry is Chinese and Indian" (p.38). In spite of her phenotype, she reflects: "I found it difficult to identify as Chinese since my father's Chinese relatives did not accept us as Chinese" (p.40). She elaborates: "Because of ... intense divided loyalties in my family, and my mother's racial way of interpreting them, I think I felt a pressure to choose to identify with my Indian or Chinese side, and found it much easier to identify with the Indian side" (p.40). Lowe Shinebourne's own description of how elements of race, phenotype and social expectations acted upon her identity formation and became an interrogation of her sense of self suggests that the rigid multicultural model cannot suffice to resolve more complex issues in mapping Guyanese identity - individual or national.

Melanie Pooch (2016) emphasises that "Multiculturalism tends to entail clear-defined and differing cultures within one society and thus, the prefix 'multi' can create borders, boundaries, and categorizations of different cultures.... [Multiculturalism focuses] on the division of the different cultures..." (p.50). Similarly, Jennifer L. Eagan (2015), bringing the three terms race, ethnicity and culture together, also highlights that multiculturalism is "the view that cultures, races, and ethnicities, particularly those of minority groups, deserve special acknowledgement of their differences within a dominant political culture" (para.1). In the case of Guyana, the 
dominant culture would have been the (ex)coloniser's British influence on the landscape, impacting systems such as law, education, economics, religion and language. Therefore, the use of a multicultural model, though useful in some ways, can become problematic, for as Eagan points out: "There is the question of which cultures will be recognized. Some theorists have worried that multiculturalism can lead to a competition between cultural groups all vying for recognition and that this will further reinforce the dominance of the dominant culture" (para.7). Thus, as Pooch clearly points out that "The crisis of the individual is frequently intensified in a multicultural context" (p.41) and so it is evident that Lowe Shinebourne and her mother through fixed cultural conceptualisations appear to have struggled to negotiate their individual racial and ethnic identities and their ongoing constructions of cultural identity birthed by the uneven forces of dominance on their colonial landscape. They needed more flexible models and terminologies suited to their conditions, rather than the one modelled after the colonial regime. Max Fisher (2013) in studying the Harvard Institute for Economic Research's map on world ethnic diversity (2002) remarks on the ethnic homogeneity of European countries stating that: "A number of now-global ideas about the nation-state, about national identity as tied to ethnicity and about nationalism itself originally came from Europe....in most of Europe, ethnicity and nationality are pretty close to the same thing" (para.11). Thus, there is a high probability that Guyana has struggled with defining a more fluid national identity having focused on the rigid 'land of six peoples' model, which was clearly based on a combination of race and ethnicity, with hopes that this basis would seamlessly translate into national identity. Fifty plus years after independence, Guyana still struggles with selecting an approach fitted to its condition, perhaps because the impetus for the multicultural approach originated from an ethnically homogenous ideology. On Guyana's post-colonial landscape, the equation that racial and/or ethnic groups equals national identity cannot suffice. Thus, it is crucial to match suitable models and terminologies to the relevant cultural situations.

In his introduction to Fernando Ortiz's Cuban Counterpoint: Tobacco and Sugar, Bronislaw Malinowski (1940) suggests that the terminologies which we use to understand ourselves culturally can either complicate or liberate our existence:

There is probably nothing more misleading in scientific work than the problem of terminology... of finding the expression that fits the facts and thus becomes a useful instrument of thought instead of a barrier to understanding. It is evident that quarreling over mere words is but a waste of time; what is not quite so apparent is... when we adopt a term whose component elements or basic meaning contains certain false or misleading semantic implications from which we cannot free 
ourselves....

By highlighting how the use of a term such as acculturation creates complications in the power dynamics of peoples versus the use of Ortiz's coined term transculturation which implies more mutually balanced dynamics between peoples, Malinowski illustrates the need to be more meticulous with our choice of terminology in mapping identity.

Alluding to Cuba's history of the arrival of peoples, Ortiz in his chapter "On the Social Phenomenon of 'Transculturation' and Its Importance in Cuba" proposes that the term transculturation implies an exchange of cultural influences between and among peoples and ultimately the creation of a new culture, unique on its own, which Malinowski in his introduction acknowledges

... a process in which both parts of the equation are modified, a process from which a new reality emerges, transformed and complex, a reality that is not a mechanical agglomeration of traits, nor even a mosaic, but a new phenomenon, original and independent. [It is]... an exchange between two cultures, both of them active, both contributing their share, and both co-operating to bring about a new reality of civilization.

Guyana, that shares some similar aspects of arrival and contact of cultures as Cuba, has undoubtedly experienced and is experiencing transculturation(s), so that now the landscape is and continues to be its own unique 'culture.' In practice, to use Ortiz's term and Malinowski's interpretation of it, transculturations have already occurred and are occuring in Guyana. Therefore, to try and separate racial and/or ethnic groups into cultures in theory is misdirected. Further to try and perceive identity in a separatist manner in theory is even more complicated, when in practice it in fact is not. Against such a conceptualisation, the use of the multicultural model as presented in the 'land-of-six-peoples' axiom becomes confounding and inadequate in understanding self. It becomes a terminology that limits Guyanese individual and national identities.

What Lowe Shinebourne and her mother needed instead in that moment of identity struggle was a different measure of conceptualising identity, the kind of measure put forth by Stuart Hall (1989): "Perhaps instead of thinking of identity as an already accomplished historical fact...we should think, instead, of identity as a 'production', which is never complete, always in process, and always constituted within not outside, representation" (p.68). This is more evident now in the 21st century for as Pooch says: Culture itself is a construct that aims at describing ways of life, customs and traditions as well as further similarities of individuals or groups. Shared language and heritage usually define the common ground for a specific cultural group. The acceleration of cultural flows, 
the interconnectedness of cultures, and the porosity of borders, however, is highlighted and furthered in the age of globalization.(p.38) Further, as Miquel Rodrigo-Alsina and Pilar Medina-Bravo (2016) explain of globalization and the multicultural model: “....although an increase in information about cultures increases visibility, it does not imply greater interaction between peoples" (para.14). Therefore, it does not follow naturally that a multicultural model is best suited to a multicultural society. Neither, does the use of a multicultural model ensure a measure of contact between peoples, a contact that is ironically already exisiting in practice.

Mary Louise Pratt's (1991) term contact zone seems useful in evaluating the effectiveness of the cultural models interrogated and explored in Jan Lowe Shinebourne's fiction. Pratt explains that the use of the term contact zone can "... refer to social spaces where cultures meet, clash, and grapple with each other, often in contexts of highly asymmetrical relations of power, such as colonialism, slavery, or their aftermaths as they are lived out in many parts of the world today" (p.34). In her speech, "Arts of the Contact Zone," Pratt gives the example of how her young son's use of baseball cards allowed him to experience the world in areas such as literacy, mathematics, history, geography and sociology. With Pratt's example and definition, I would infer that when each contact zone is, or the interactions in that contact zone are, realised or maximised, the possibility of awareness, or in the case of this essay, the possibility of mapping self in a more holistic and less separatist manner, increases. If Ortiz's proposition that transculturations are constantly in motion from the moment of contact and thereafter, then a contact zone has already been inadvertently established in all transculturations. Therefore, the multicultural model popular in Guyanese elementary schools raises the question of why should the population operate under the assumption that each group of peoples retains a separate culture. It appears possible for transculturations to occur even while each of the six groups keeps itself theoretically distinct; this illusion of distinctness then leads in turn to the group enacting and enforcing the practice of individual cultures when in reality, like the variations in Lowe Shinebourne's and her mother's individual experiences, the degree of transculturations varies and is uneven from case to case, but nevertheless present.

I suggest then that since neither individual nor national identity is fixed, but since the use of the multicultural model is so deep-seated in Guyana, that the population could find the study of Lowe Shinebourne's explorations of and gradual movement from the more fixed multicultural model towards more fluid models of mapping cultural identity, implementable. In this paper, I employ Pratt's term contact zone to approximate the amount of contact and (ex)change that each cultural model explored in Lowe Shinebourne's fiction yields. I approximate the yields on the premise that operations within contact 
zones must be consciously maximised before any significant (ex)change can be effected.

Lowe Shinebourne's first novel Timepiece, set in the 1960s, is not timid in addressing the impact of the separatist multicultural model on the Guyanese youth. The protagonist Sandra Yansen and her friend Son Young broach the topic of how others' treatment of your race could confound your identity altogether: "Sandra asked, 'Why did it hurt when they called you a Buck [derogatory term for Amerindian]?"” and Son replies, "I think it made me feel confused, not sure who I was"” (p.168). Son's experience of identity is confounded by whoever he feels himself to be versus the stock identity his society expects him to have. If taken as the author's introductory novel on the study of identity and race in Guyana, Timepiece launches the exploration of models for negotiating the complexities of a Guyanese identity through Sandra's reflection that "Race is the worst problem in Guiana. It's a xenophobic country, maybe because we have so many races and we don't have a philosophy to accommodate all of us" (p.169). Sandra's analysis interrogates the multicultural model and opens avenues for selecting other models by allowing the reader to ask: How can one philosophy be used in a society that is not homogenous? What kind of model to negotiate identity can possibly be employed in a country that not only conceives of itself as multiracial but simultaneously carries the other slippery labels multiethnic and multicultural as well? Further, how can a clearly defined yet flexible approach be employed to both accept and challenge the ambivalent multicultural perspective and accommodate more dynamic cross-cultural, intercultural and transnational measures of mapping the Guyanese cultural identity in the $21^{\text {st }}$ century?

In her second novel The Last English Plantation, Lowe Shinebourne extends her thesis one step further by showing through the character Lucille's ravings some of the early complications in the composition of the Guyanese identity: "This is the West Indies, not India, not Africa, not China, the West Indies! We are British" (p.124). Here, Lucille represents a population that grapples with the apparent contradictions of its identity. By choosing to identify with only the culture that dominated through regime, Lucille sees herself and Guyana as having a rigid identity. By denying racial heritage, newer ethnic alliances and the constantly changing cultural landscape, Lucille operates with a model that is inadequate for her condition as it has potential to encourage war within herself and her circles. In Lucille's case, the operations in the contact zone with herself and British culture are maximised but are ignored or minimised in the other contact zones. Similarly, Son Young's society imposes a theoretical separation of contact zones and isolates him forcefully to identify only with his 'racial group,' something which he himself does not do. 
To address these complications, Lowe Shinebourne advances her thesis again by allowing her minor characters Mrs. and Mr. Searwar in The Last English Plantation to oppose views like Lucille's. Mrs. Searwar says that "...there was a lot of racial misunderstanding in the country, but education would solve the problem...the Caribbean was a multiracial place, [and] it was important to respect each other's cultures" (p.117), while Mr. Searwar, contrary to Lucille's interpretation of herself, situates himself with an identity synonymous with his new post-colonial national state: "I am Guianese, not British like some people say they are, but Guianese" (p.148). Mrs. and Mr. Searwar's approaches open avenues for more questioning: what it means to be Guyanese and what models can be successfully used in a multiethnic society to construct healthier individual and national identities.

As such, apart from the controversial multicultural model, there are other models that can be employed in the negotiation of self, such as the crosscultural model which "deals with the comparison of different cultures.... differences are understood and acknowledged, and can bring about individual change..."; however, it should be noted that this model does not allow for "...collective transformations. [As] In cross-cultural societies, one culture is often considered 'the norm' and all other cultures are compared or contrasted to the dominant culture" (Schriefer, 2016, para.3). Lowe Shinebourne in her gradual move to conceptualise identities more fluidly, attempts the application of cross-cultural exchanges in The Last English Plantation and in her third novel, Chinese Women.

In The Last English Plantation, Lowe Shinebourne applies the use of a cross-cultural approach to negotiate the relationship between the (ex)coloniser and the (ex)colonised. In negotiating the coloniser's past role on the Guyanese landscape, she shows that it is not as straightforward as ascribing all the negative qualities of humanity to just one race and all the positive qualities to another. Thus, the protagonist June Lehall in The Last English Plantation cannot process why she was "...feeling sorry for the white girls." The binary codes in play cause her to contemplate that there must be "...a traitor somewhere inside her to make her feel sorry for them" (p.31). But June's inclinations to pity the girls show a decolonising process in which the ex-colonised subject is neither in pursuit of oppressing the former oppressor nor relinquishing human power to retain the role of victim. Instead, she claims equal humanity by feeling sorry for who needs feeling sorry for, regardless of who they are. The older construction of oppressor-victim is challenged by June and so June becomes an example of attempting the use of a cross-cultural model by trying to understand what the overseer's daughters Sarah and Annie Beardsley's experience might be like.

In like manner, the use of the cross-cultural model is applied more in depth in Chinese Women, the novel which appears to have the first extensive 
exploration of an individual seeking to understand self by maximising operations in a contact zone with another group other than the coloniser's group and it is therefore the novel on which I will linger for a while.

Using a cause-effect paradigm, Lowe Shinebourne problematises the formation of pre-independent Guyanese identity. She uses her protagonist Albert Aziz to trace how colonisation resulted in a racialised construction of relationship between the colonised and coloniser, a model that was then transferred to negotiate other relationships among the various groups of people in the country. She then proposes a solution by allowing Albert to internalise the inadequacy of this old transaction and to attempt the use of a cross-cultural perspective in the mapping of his identity.

To begin with, from Albert's perspective, the coloniser is the image of all things negative but at the same time the force and framework through which he weaves his identity. Pooch in synthesising the ideas of Beise (2002), Bhabha (1994), Young (1995) and Roh-Spaulding (2002), explains such a paradox: "The colonizer-colonized relationship goes beyond dependence. It is of interdependence and mutual influence, changing both of the cultural identities. Thus, neither side of the discourse is left untouched. This influence, however, is unbalanced due to the colonizer's power" (p. 44). These exact dynamics are seen in Albert's paradoxical relationship with the Europeans. On describing the starvation, poverty and nightmares in pre-independent Guyana, he says that "To grow up on a sugar estate in British Guiana when I did, at the height of British colonialism ... made you nervous and anxious" (p.38) and that "...very little divided beast and men" (p.34). Further, he emphasises the spectator-like identity of the (ex)colonised in the white man's world, thereby identifying race as the determining factor in zombifying and excluding them from the benefits enjoyed by the coloniser: "The worst fate of the Black slave or the East Indian coolie was to be a spectator of the white man's lifestyle, knowing it was unattainable, knowing that he was forever orphaned from the white man's high standard of living, his wealth, property, luxuries, and his women" (pp.30-31).

Yet, after he falls out of a tree badly injuring himself, Albert's recovery takes place at the hands of an English doctor: "Painstakingly, slowly, Dr. Webster reset my joints and ligaments until they grew back and I became whole..." (p.15). Dr. Webster recreates Albert from nothing when Albert's own countrymen, descendants of labourers like himself, would not care for him. In isolation, Dr. Webster's medical treatment for Albert can be seen as remarkable, and yet, it is the power dynamics and how they affect Albert that calls this relationship into question. It is the kind of power dynamics to which Hall refers when he says that: ...Europe was a case of that which is endlessly speaking - and endlessly speaking $u s$ [the Caribbean]. The European presence thus 
interrupts the innocence of the whole discourse of 'difference' in the Caribbean by introducing the question of power. 'Europe' belongs irrevocably to the question of power, to the lines of force and consent, to the pole of the dominant in Caribbean culture. (76) As a result of Dr. Webster's interruption, Albert's healing process is not an empowering community venture on the part of his family and countrymen, but is a cold scientific interdependence through which he is disempowered as he is studied and catalogued like a subject: “...I was his little miracle.... He wrote papers about me and published them in England. $\mathrm{He}$ showed me the medical journals they appeared in" (p.15). In the same breath that Dr. Webster treats Albert "like a son" (p.15), he treats him like a lab rat. This leads to Albert continuing to map his identity based on race, seeing himself only as: “...this dark brown Indian teenager with the disjointed arms and legs, who moved like a robot, a clockwork creature that was once broken and had to be pieced together again by a white doctor who set his springs and screws again, who wound me up with a key and let me out so I could wind my way around his world" (p.31) - a world in which the ex-colonised are powerless to choose new models of negotiating self.

The multicultural model therefore maintains the separation of groups through the 'question of power.' As a result of experiences such as these, the ex-colonised retain the binary conceptualisation of groups of people: coloniser-colonised, powerful-subjected. By transferring the structures they used to negotiate their colonial relationships, these groups begin to pit their racial differences against each other, thereby constructing the country's foundational pre-independent identity through a framework of race instead of through the unified purpose of living in a new homeland. For instance, Albert remarks of the Africans and East Indians: "...they guarded their separate lives, jealously resenting and wishing the worst on each other" (p.12). Their experiences force them to believe that race was the sole factor in taking and losing power and therefore in determining their identities and survival. Their initial contact zones with the coloniser are so impacting that they interrupt the 'innocence' of any unified purpose that the groups might have and in turn encourages continued segregation through assumption of invented power. Through Albert's experiences, we see how race-relations born out of an inadequate multicultural conceptualisation of self, intersect with other variables such as colourism, education, religion and family life and impact identity formation negatively.

Colourism fragments the Guyanese society: "The British ruled at the top, so their white skin became a status symbol. They enslaved the brown Indian and Black African. The lighter your skin colour, the higher your status, the darker, the lower. The Portuguese also came to the country to work as labourers ... but because their skin was white, they became second in power to 
the British" (p.11). In the example given, the Portuguese are equal to the other racial groups as labourers, but they were 'more equal' than anyone else only because of their skin colour. Following in this colonialist construction of identity, the 'hierarchy' of skin colour positioned the mixed 'educated' group as second on the ladder and then finally the rest of the population depending on the shades of their complexion. Pre-independent Guyanese identity was therefore constructed on "codes of racial snobbery and prejudice" (p.11), inherited, as Albert says, by "... the society [that] the British [had] created for us to live in, a racist society" (p.11).

Moreover, religion, intersecting with the variables of racism and classism, acts as another means of taking power by exclusion. These variables operate in Albert's futile struggle for visibility where persons are always putting others beneath themselves: his family put their newly acquired 'English' lifestyle above the Blacks, while the Hindus in turn put their religion above the Muslims - "They wanted to ensure they were not at the bottom of the pile in Guiana...so they put us, their fellow Indians, in that position instead" (p.14) - referring to them as Fulamen, "after the African Muslim Fulani tribe" (p.10), thereby creating a racial lens through which to interpret religion in order to continue the created differentiations of race and power.

Racial coding also affects the supposedly safe family unit. Lowe Shinebourne shows how the aspiration to imitate the white upper class eventually fragments the family unit. Albert sees their move to Berbice as choosing status to elevate the 'lowliness' of their 'racial position' at the cost of their familial bonds; while lying in the hospital in Georgetown, he begs them not to move to Berbice which is miles away, but "...they laughed and said Berbice was 'the land of milk and honey', and they had to go" (p.9). This move from Enmore, where they had been "dirt poor" (p.9), appears as their ticket out of the bracket of 'colonised low class' to 'freed upper class': "At fifty [years old], to be offered a job in Berbice in senior management, to become an overseer among the expatriate white overseers, was to reach the very top. It elevated him [Albert's father] beyond the dreams of most Indian men in the colony" (p.9). Not accepted by the Hindu Indians, and not aligned with the Africans who "had long escaped the sugar plantation and...joined the middle class by becoming Christian and educated..." (p.10), the Azizes feel alienated by either race, education or religion, and so when the opportunity for an overseer's position appears, the Azizes lose no time in assuming 'white personas' with which to feel superior to the others who had subjugated them. Most devastatingly to a young boy, when his father's promotion appears to finally confront the variables that had marked their alienation, Albert's worth in his family is radically reduced and he is deserted in favour of the pursuit of the new status. In assuming the 'qualities' once ascribed to a 'superior race,' the Aziz family turn themselves upon themselves, proving once again that 
racial codes control even the family unit. Among other things, Mr. Aziz destroys his family by transferring the corporal punishment and violence of the plantations to his daughters who shriek and cry at being whipped and who "blubbered inhumanly in their sleep" (p.19). No liberation can come for Albert from within his own family.

In addition, Lowe Shinebourne does not exempt her protagonist from being prejudiced, as on his release from the hospital, he arrives at his new house in Berbice and admits that he "looked forward to living like a little white man" (p.17). It seems as if the only way he thinks he can free himself is by mimicking the oppressor's actions of subverting others by taking power. Albert engages in mimicry, described by Pooch as "... an act of replication or camouflage in which the colonized unconsciously tries to become like the colonizer" (p.44), and as a boy, he comes into feelings of pride and selfhood mostly through racial codes, thereby suggesting that identity, power and racial coding are synonymous in his society. In addition, he tries to code himself as superior through racial and slanderous slur by saying things like "Everyone knows Englishmen are all homosexuals" (p.15), thereby deflecting feelings of inferiority from himself onto the Englishmen and directly attacking the image of what Pooch refers to as "the putatively universal" that is the "white, male, and heterosexual" (p.45). It is difficult for Albert to ever be free from the prejudice of the prejudiced society that created him.

Ultimately, for Albert, there seems to be no liberation that can come from his own racial group, his own colour or class, his own family or even himself, or from the whites or the Hindus or the Africans who are embroiled much too closely in the race, colour, class or religious war with each other and therefore with him, especially if the variables continue to operate in the same manner constantly. To manage these complications, he must look outside of his current framework for a psychologically healthier and more holistic solution to his condition. Yet, liberation would still have to come from within the confines of his country's own history and social dynamics.

In Albert's case, his salvation comes from his cross-cultural experiences with the Yhips and the two eponymous Chinese women - Anne Carrera and Alice Wong who seem to be the redemptive map through which he eventually chooses to read his life. Albert's turning to them allows him to soothe his anguish and find some salvation in a space that is to a greater degree, more neutral than the other groups to which he had been exposed, for as he says: "The Chinese were not implicated in the racial politics...this gave Alice a neutrality..." (p.53).

Against the backdrop of neutrality provided through the Guyanese Chinese that he knows, Albert sees the Yhips and their shop as a nurturing model, separate from the human degradation of the plantations: "There was only ever one thing that gave me relief from my fear and terror of East Indian 
poverty - the Yhips' shop, or as people called it, the 'Chinee shop'" (p.38). Human restoration comes to him as he marvels at how Mrs. Yhip prepares the sandwiches "almost lovingly" (pp.39-40) and how the Yhips nurse the less fortunate and even hand out food for free: "I never saw the Yhips receive thanks or praise for their hospitality. People on the estate were not accustomed to human decency and acts of kindness...", instead they were conditioned and accustomed to "racial abuse and cruelty" (p.40). In childhood, and later in adulthood, where the model to which he is initially exposed falls short, Albert is unafraid to go in search of another model: in the Yhips' shop he says: "...those scents had a sedative effect on me. They always have done, and still do. The effect of Chinese people and their food and culture was always to give me a sense of peace - it was the best medicine for me" (pp.40-41). Albert sees that his identity could be constructed based on another model than that to which he had been exposed. By observing the stark contrast between the dislodgement of self that comes from racism and the brute conditions of plantation life versus the harmonious wholeness within himself that comes from merely watching the Yhips weave their lives in the community, he discovers a psychologically healthy mode of human sustenance. The Yhips bring to life and nurture his affective dimensions, so much so that he emphasizes more than once: "It was not only the delicious smells and sight of food we spectators went to the shop for, but also to see the gestures of kindness and mercy the Yhips performed. Growing up on a sugar estate, it was the only civilized behaviour I ever knew" (p.41). The Yhips fill a maternal role on the harsh plantation landscape at a time when Albert's affective side feels like an orphaned child. The Yhips' shop physically embodies a more accommodating structure for Albert's unstable identity, providing human contact that defies the old racial framework.

Similarly, in Anne Carrera's free movements and easy laughter with her own sons, a manner that contrasts his mother's trapped identity in which she merely gossips and racially profiles others, Albert attempts, though unsuccessfully, a rebirth, in which he ventures onto the Carrera's lawns and falls and lies like a "foetus" (p.23). By reaching out for Anne to take his arm and save him, he chooses a newer cultural model of mapping self. Though his mother arrives to wrench him away from any kind of cultural rebirth that his contact zone with Anne might offer, it is important that Albert can see in someone else's life the possibility of a model of rebirth for his own life. In the same way, Albert seeks out Alice Wong for the intimacy of her friendship and the community of her family. He details: "My friendship with Alice became the most important thing in my life.... and [I] concluded love was the warm feeling of security, comfort and satisfaction I felt in her home, in the presence of her family when the air was full of the scent of cakes baking in the oven, and Chinese food being cooked in the kitchen" (p.51). Though the Wongs 
eventually banish him from their home because of his race, even as they too inherit the prejudices of their society, Albert takes with him for the rest of his life the calming effect of sitting in the Wong home and pretending that he could assimilate into the wholesome effects of their 'Chinese culture.'

Albert consciously crosses over into a contact zone where he can see the Chinese as set apart from the brutality of the colonial regime, as being allowed to keep their humanity. It is their humanity that he sees as the solution to his own race, colour, class, religion, even health problems. What he cannot access in his own racial and ethnic groups or in the groups more obviously at open war against him, he unabashedly tries to access in another group. It is important to note however, that the text does not suggest that Albert's redemption miraculously comes from the Chinese heritage itself as an isolated variable, as Albert clarifies: "Anne Carrera's ethnicity was of no real interest to me. It thrilled me to watch her play with her sons and sent something like an electric charge through me that made me feel strong" (p.27). Albert is not necessarily opposed to or fanatically devoted to any one racial group or cultural lifestyle itself, rather, he manages to find salvation through crossing into a zone where he can attempt a fusion of himself with others' kinder qualities.

In both of Lowe Shinebourne's cross-cultural explorations - June's from The Last English Plantation and Albert's from Chinese Women, the protagonists are willing to open themselves to understanding and experiencing another group's reality. The result in June's case is to freely feel empathy for the other group, thereby making herself more emotionally liberated, rather than having her affective dimension dictated by the old social norms of regarding the 'coloniser' only in a negative light. In Albert's case, by opening his consciousness to another group, he allows himself to immerse in and learn positive elements of their lifestyle. Altogether, through his insistent search for another way of interpreting himself outside of the old racial framework, Albert manages to explore a cross-cultural model that could help him negotiate his identity. Firstly, he allows the Yhips to plant the seed of sharing their resources with the rest of society. By learning from them, he unlearns some of the harsh codes of social interaction that he adapted from the relationship with the coloniser and he plants ideas of cultural tolerance and human exchange. Through the Chinese that he knows, he realises that his usual measures of viewing himself can be readapted against another cultural approach - that of provision, sustenance and freeness, as opposed to skin colour, religion or status. However, Schriefer's conclusion that one complication of this crosscultural model is that the dominant group will fail to fully accommodate the individual seeking and experiencing change turns out to be accurate. While both June and Albert experience individual change, they are still ultimately excluded from the worldview of the contextually dominant group and there 
are no major group transformations on either side, only individual transformations. In short, though the cross-cultural model shows that the conscious cross over into contact zones is greater and the individual impact more observable than the multicultural model, the cross-cultural model still assumes the position of fixed groups that the individual must seek out at his own risk or reward.

Therefore, where this model is found inadequate, there is another option, that of the intercultural model. Of the intercultural model, RodrigoAlsina and Medina-Bravo explain:

Whereas multiculturalism focuses on the coexistence of cultures, the focus of interculturalism is cohabitation, which implies interrelationship and, therefore, potential conflict. In multiculturalism, territory is the element that differentiates the self from others. In contrast, in interculturalism, cultures are not directly linked to a territorial identity....

(para.

In her fourth novel, The Last Ship, Lowe Shinebourne advances her movement towards the use of more fluid models yet again through one of her main characters, Susan Leo who sees her experiences through an intercultural lens. The memorable image of Susan's entrance is symbolic of her success in boldly defying the conventional model of society's coded expectations for an individual's physical appearance: "Susan Leo looked Chinese but she was dressed like an East Indian; she was wearing the short white organza ornhi, that Indian women wore on formal occasions, along with a nose ring, gold bangles, earrings and necklaces" (p.18). Susan succeeds in using a model that allows her the freedom of choice to weave her life into any cultural space on her landscape of residence. In her case, she adapts a cultural perspective that in her interpretation better suits her daily lifestyle and she manages to be accepted and integrated into another group's 'codes.' In this instance, Susan allows herself to become so flexible so that her racial heritage or the codes accompanying the heritage are not the only defining characteristics of her identity. She redefines her identity despite the codes fixed for her, weaving in and out of any available culture suited to who she chooses to become on her new landscape.

However, the use of such a model, as with most models, opens itself to further interrogation and criticism. In such a model, "in a situation of intercultural dialogue, one must consider what aspect of identity to emphasize; in other words, one must choose what aspect of identity will interact with the other" (Rodrigo-Alsina and Medina-Bravo, 2016, para.23). Pitfalls such as being accused of cultural appropriation, or self-racism and experiencing further invisibility or rejection are also possible. As Rodrigo-Alsina and Medina-Bravo

remark:

The main problem [of inter-culturalism] is not the identity I 
attribute to myself, but whether I have enough influence to ensure that that identity is recognized by others. Here, questions such as the following arise. In what category does the other place me? Will they relate to me from a category alien to my identity, but which they still attribute to me and from which they will relate to and evaluate me? (para.24)

Ultimately the question remains whose group image would be more preferred and emerge dominant and does this dominance not contradict the very purpose of intercultural exchanges? So though in using this model the operations in the contact zone are more consciously chosen and visibly enacted, more so than both the multicultural and cross-cultural experiences, there still remains the stigma that someone is operating in a cultural space that is not theoretically originally meant to be his and he is therefore judged positively or negatively by others for operating within that space.

Finally, in her collection of short stories - The Godmother and Other Stories, Lowe Shinebourne explores the transnational model of mapping self as many of her characters are Guyanese emigrants seeking to negotiate their identities across national borders. Nina Glick Schiller, Linda Basch, and Cristina Szanton Blanc (1995) define transnational migration as the process by which immigrants forge and sustain simultaneous multi-stranded social relations that link together their societies of origin and settlement" (p. 48). The character Sylvia in "Hopscotch," for instance, says that "Suffolk [England] is flat like Guyana" (p.60); the eponymous Godmother prepares a Guyanese meal in her cold English kitchen as memories of the land of her birth are superimposed on the steam from the pot on her new landscape of residence; the protagonist of "London and New York" never fails to search for the foods from her homeland regardless of which landscape she is in - the English landscape as a resident, or the American landscape as a tourist. The protagonists in many of the stories constantly negotiate themselves back and forth across national, geographic and cultural borders with the criss-crossing and layering of influences from both spaces.

In these examples of the transnational model, cultural groupings often visibly separate themselves from race and are attached to notions of nationalism instead. This is evident when a migrant character's race and or ethnicity is not foregrounded; rather their 'Guyaneseness,' whatever it is meant to be, is foregrounded. As a result of this, the new cultures compared are Guyanese 'culture' and British or American 'culture' or wherever the migrant land might be. In this model, all of the afore-mentioned 'six' groups of peoples often appear to become one unit and from the diaspora therefore constitute one contact zone - home. In such cases, it is easier to find that racial or class tensions otherwise emphasised at 'home' can become collapsed or minimised when engaging with someone from home away from home. 
In summary then, taken as a body of work, Lowe Shinebourne's novels in their chronological order of publication, along with her collection of short stories progressively attempt to illustrate the possibilities of using alternative models for mapping identity. In her first two novels, Lowe Shinebourne carefully uses her space to problematise the implications of race and race relations in Guyana, while in her second two novels she builds on the framework of the first two, this time moving towards more fluid solutions. Her pieces demonstrate the necessity of closely examining the individual's or the population's condition, becoming aware of the various cultural models that can be used to negotiate identity in that condition and choosing the model best suited to the individual or group's condition in a particular context.

Through Sandra, Son Young, Lucille and the Searwars, it becomes easier to see that adherence to the fixed and segmenting nature of the multicultural model can become limiting and problematic in a society that is already struggling with defining individual and national identities in a more fluid manner. With June and Albert, the author crosses into theoretically forbidden contact zones, where June tries to make meaning of her own life by feeling empathy for the overseer's children, and Albert, in refusing to know his 'limits' in childhood crosses over into another 'culture' where he boldly seeks the benefits of cross-culturalism by coveting the memory of the Yhips' shop, reaching out to Anne Carrera and seeking out Alice's company. Then through Susan Leo, the author illustrates the merits of cultural choice and forces us to contemplate ways in which Guyanese have avoided conscious use of the intercultural approach. Finally, through characters like Sylvia and the Godmother and others a whole world of transnational interplay opens up to the reader. Altogether, the relatable struggles of these characters as they are studied chronologically can allow the local reader to become open minded enough so as to deviate from his elementary level curriculum.

In selecting a suitable model for negotiating the self, the ultimate goal ought to be "...to find deeper, more sensitive ways of seeing ourselves and each other, as human beings, souls with real, similar emotional and spiritual needs, not just racialised brute species" as Lowe Shinebourne says in her interview with Annie-Marie Lee-Loy (2008, p.44), even as the individual confronts and facilitates whatever 'contradictions' and complications he meets, which he inevitably will. Annie-Marie Lee-Loy (2009), for instance, identifies the dilemma of the Caribbean saying that ...one must also recognize that the claim for cultural synthesis in the Caribbean paradoxically both denies and reinforces cultural differences.... In other words, statements such as Jamaica's national motto 'Out of many, one people' or Guyana's popular description as a land of six peoples, ironically highlight and reinforce ideas of stable cultural differences at the same time that they seek to overcome such 
differences.(p.294)

Even the cross-cultural and intercultural models appear to be subsets of the multicultural model or at any rate, they appear to only be able to function because the multicultural model is in fact their premise. After all, how can groups cross over into and maximise their contact zones if there are no fixed groups to begin with? Yet, the population must realise that an inappropriate or ambiguous choice of model can, for years or decades, affect identity formation in the already often paradoxical postcolonial space and that the model that may have worked in one country or in one era or context may not work in another, or the model that may work for one individual may be ill-suited to another; after all, there was once a time when 'multicultural model' was a wholly positive, fashionable and empowering term to use. Therefore, one must constantly be exploring the use of models to match the complexity of the outcomes of the fusion of many heritages and the uniqueness of our experiences in Guyana and the Caribbean and in the relationship with our diaspora, mindful that each new conceptualisation brings with it its own solutions or resolutions as well as its own complications.

As Rodrigo-Alsina and Medina-Bravo express in their own conclusions: "It is not easy to let go of our prejudices, but it is even more difficult to modify our modes of thinking and our classificatory routines and to change our outlooks and perspectives. However, what seems clear is that we are living through a period of historic change that is leading to a shift in paradigms in cultural issues " (para. 33). After all, even before Guyana gained independence and emphasised its axiomatic 'land-of-six-peoples' concept, Ortiz was conceptualising in his term transculturation, a more collapsible framework from which to view the changing of a whole cultural landscape. Further, even as Guyana struggles to define its national identity, a globalised twenty first century world appears to be moving towards the concept of postnationalism: frequent travellers identify themselves as global citizens or children of the world; overseas students or members of the diaspora identify in unequal portions with the cultures to which they are exposed; culture travels to Guyana via the internet, television, radio; millennial and generation $\mathrm{Z}$ Guyanese share the American culture in the fast foods they choose, the clothes they wear and the movies and music they favour, even adapting on occasion, an American accent. In some cases, there is a strong possibility that Guyanese are more willing to reinterpret themselves as North Americans rather than as products of intercultural exchanges among the ethnic groups already existing in the country. These fluid conceptualisations of self then raise further questions such as: if we are moving towards a global culture whose standards will we take, for whose 'globe' is it? In addition, more recently, the face of Guyana's landscape has been rapidly changing with the emigration of large numbers of the population to North America and Europe, and the immigration 
of Chinese, Cubans and Indian nationals, as well as the circulation of Brazilian and Venezuelan influences in various sectors. Further, the influences of other persons of other nationalities who have moved to Guyana to live and work by appointment, marriage or volunteerism are also a part of the transcultural exchanges taking place. In addition, the recent oil and gas findings are also currently influencing the cultural landscape. Transculturations are occurring even as Guyana grapples with its old axiomatic conceptualisation. Therefore, in future, without using appropriate concepts to analyse the ongoing transcultural negotiations, living in a multi-ethnic and multinational space could become fragmenting and alienating. Altogether, the understanding and choice of model for negotiation of identity requires careful thought.

In this time where there are sometimes paradoxical but fluid conceptualisations of identity, it seems woefully wanting to choose to map identity with a more rigid and probably problematic model. After abandoning the old racial codes of identity construction, Guyanese must begin to employ instead conceptualisations that are more suited to our dynamic condition, while being mindful of the complications of the use of each model. Ultimately, Shinebourne's collective presentation provides an exemplar for Guyana's nation building, a gradual theoretical resolution for race relations and building human relations and concrete illustrations for negotiating individual identities.

\section{References:}

1. Eagan, Jennifer L. (2015, August 31). Multiculturalism. Encyclopaedia Britannica. Encyclopaedia Britannica, Inc. Retrieved from https://www.britannica.com/topic/multiculturalism.

2. Fisher, Max. (2013, May 16). A Revealing Map of the World's Most and Least Ethnically Diverse Countries. The Washington Post. Retrieved from https://www.washingtonpost.com/news/worldviews/ $\mathrm{wp} / 2013 / 05 / 16 / a-r e v e a l i n g-m a p-o f-t h e-w o r l d s-m o s t-a n d-l e a s t$ ethnically-diversecountries/?noredirect=on\&utm_term $=.6 \mathrm{f} 1 \mathrm{c} 884 \mathrm{e} 70 \mathrm{ef}$.

3. Glick Schiller, Nina, Linda Basch and Cristina Szanton Blanc. (1995). From Immigrant to Transmigrant: Theorizing Transnational Migration. Anthropological Quarterly 68: 48-63. Retrieved from www.jstor.org/stable/3317464.

4. Hall, Stuart. (1989). Cultural Identity and Cinematic Representation. Framework: The Journal of Cinema and Media, (36), 68-81. Retrieved from http://www.jstor.org/stable/44111666.

5. Lee-Loy, Annie-Marie. (2008, March). An Interview with Janice Lowe Shinebourne. The Arts Journal: Critical Perspectives on Contemporary Literature, Art \& Culture of Guyana \& the Caribbean, 
Volume 4, Numbers 1 and 2, 38-44. Retrieved from EBSCO HOST, Database: Caribbean Search.

6. Lee-Loy, Annie-Marie. (2009). Saying No to Chineseness: The Possibilities and Limits of a Diasporic Identity in Janice Lowe Shinebourne's Fiction. Journal of Chinese Overseas 5, 291-309. DOI:10.1163/179303909X12489373183019.

7. Lowe Shinebourne, Jan. (1986). Timepiece. Leeds, England: Peepal Tree Press Ltd. (New edition 2012.)

8. Lowe Shinebourne, Jan. (1988). The Last English Plantation. Leeds, England: Peepal Tree Press Ltd. (New editions 2002, 2011.)

9. Lowe Shinebourne, Jan. (2004). The Godmother and Other Stories. Leeds, England: Peepal Tree Press Ltd. (New editions 2011, 2013.)

10. Lowe Shinebourne, Jan. (2010). Chinese Women, A Novel. Leeds, England: Peepal Tree press Ltd.

11. Lowe Shinebourne, Jan. (2015). The Last Ship. Leeds, England: Peepal Tree Press Ltd.

12. Mc Gowan, Winston. (2018). A Survey of Guyanese History - A Collection of Historical Essays and Articles by a Guyanese Scholar. Georgetown, Guyana: Guyenterprise.

13. Ortiz, Fernando. Cuban Counterpoint: Tobacco and Sugar. Knopf Doubleday Publishing Group. Kindle Edition.

14. Pooch, Melanie U. (2016). Cultural Diversity in a Globalizing Age. DiverCity - Global Cities as a Literary Phenomenon: Toronto, New York, and Los Angeles in a Globalizing Age. Transcript Verlag. Retrieved from https://www.jstor.org/stable/j.ctv1wxt87.7.

15. Pratt, Mary Louise. (1991). Arts of the Contact Zone. Profession, 3340. Retrieved from http://www.jstor.org/stable/25595469.

16. Rodrigo-Alsina, Miquel and Pilar Medina-Bravo. (2016, March). A Reflection on Identities, Culture Models and Power. Journal of Intercultural Communication, Issue 40. Retrieved from https://immi.se/intercultural/nr40/rodrigo.html.

17. Schriefer, Paula. (2016, April 18). What's the difference between multicultural, intercultural, and cross-cultural communication? Culture Articles. Spring Institute. Retrieved from https://springinstitute.org/whats-difference-multicultural-intercultural -cross-cultural-communication/.

18. Thomasson, Frank. (2009). A History of Theatre in Guyana 18002000. London \& Hertfordshire, England: Hansi. 